Philosophical Engagement: Davidson's Philosophy and Chinese

Philosophy, Bo Mou (ed.), Leiden: Brill Academic Publishers, 55-71, 2006.

\title{
Davidson and Chinese Conceptual Scheme
}

Koji Tanaka

Philosophy Department

Macquarie University

Sydney NSW 2109

Australia

Koji.Tanaka@mq.edu.au 


\title{
Davidson and Chinese Conceptual Scheme
}

\begin{abstract}
In one of his influential works 'One the Very Idea of a Conceptual Scheme', Donald Davidson argues against conceptual relativism. According to Davidson, 'we could not be in a position to judge that others had concepts or beliefs radically different from our own'. Davidson's thesis seems to have a consequence for comparative philosophy, particularly in a comparative study between Chinese and Western traditions of philosophy which are often considered to differ conceptually. If Davidson is correct, it is not clear whether or not we can have insight into how and why concepts differ between these traditions.

In this paper, I philosophically reflect on Davidson's argument against conceptual relativism. Though this paper retains the backbone of his argument, I reject Davidson's thesis that different ways of conceptualisation cannot be compared. I do this through a discussion of the comparative studies conducted by David Hall and Roger Ames. In conclusion, I self-reflectively examine the nature of the demarcation between different traditions of philosophy and show how the activities of comparative philosophy can proceed.
\end{abstract}

\section{Comparative Philosophy}

Comparative philosophy is the branch of philosophy which examines and contrasts different traditions of philosophy. A comparative philosopher examines, for example, African, Buddhist, Chinese, Indian, Muslim, and Western traditions of philosophy in comparison with one another. Comparisons may be made between sub-traditions within a tradition: one may compare Confucianism and Daoism, for example. The particular concern for us in this paper is the comparative studies of Chinese and Western traditions.

One may question the legitimacy of examining Chinese philosophy and Western philosophy as if there are unified ways of talking about those philosophical traditions. It is true that there are disagreements within a tradition. Sometimes, disagreement is the force behind the development of a philosophy. However, for a comparative study to be possible, we have to generalise traditions of philosophy. As Kasulis (2002) argues, '[w]ithout the generalisation, however, people cannot proceed in their quest for 
understanding anymore than they can use most databases without first defining the fields of entry' (pp. 7-8). Of course, there are exceptions to any generalisation. None the less, they do not refute a generalisation as such; they are just exceptions. Indeed there are philosophers who argue against the main stream doctrine within a tradition. However, the fact that they are all engaged in a meaningful philosophical debate suggests that they share something in common. Otherwise, it is not clear that they can communicate with each other and contribute to the development of the tradition as a result.

By examining comparative philosophy as being based on generalisation, it may be suggested that comparative philosophy is a way of understanding philosophies of different traditions themselves: a generalisation which underlies comparative philosophy may be thought of as a way of understanding a philosophical tradition itself. In fact, Parkes (1987) suggests just that:

The major concern of comparative philosophy, however, is an understanding of the philosophies themselves - and thereby, to a greater or lesser extent, of the world. (p. 3)

For a generalisation to be possible, however, it must be assumed that there is something common that is shared by the members of the tradition. Yet how can we discover the common features that can be attributed to a tradition? And how can the comparisons of traditions be made possible based on those common features? If comparative philosophy involves generalisation to a certain degree, these seem to be the questions that are fundamental to comparative philosophy. Unless we can answer these questions, it is not clear how one can comparatively philosophise about different traditions.

\section{Special Logic Resort}

It has been suggested that each philosophical tradition has a 'special logic' of its own. According to this suggestion, Western philosophers are unable to understand Chinese philosophy since it is based on a totally different logic. The special logic resort, as Hansen (1983) identifies it, goes something like:

What makes sense to Chinese does not make sense to Westerners. ${ }^{i}$ (p. 20)

According to this idea, comparisons of Chinese and Western philosophies can be made based on the differences in 'logics' which dictate what 'makes sense'.

However, if there is 'Chinese logic' which blocks the Westerner's mind, Western philosophers would have to give up their attempt to understand Chinese philosophy. In fact, they would be unable to recognise Chinese philosophy as meaningful at all. If the Chinese indeed have a special logic which prevents Western philosophers from understanding their philosophy, then Western philosophers cannot even make sense of the idea that the Chinese have a special logic. As Hansen (1983) argues 
If Western minds are incommensurably different from Chinese minds then we could not discover anything at all about Chinese thought - including the actual details of the "logic" of Chinese. (p.14)

Thus, if we understand 'logic' according to the special logic resort, it is implausible to suggest that a special Chinese logic underlies the Chinese philosophy and that it is the special logic that makes Chinese philosophy differ from Western philosophy.

\section{Comparisons of Concepts}

In order to answer the fundamental questions in comparative philosophy, we may think of each tradition of philosophy as having built up a stock of concepts which form beliefs, knowledge, arguments, etc. For example, the Chinese associate tian as 'an ancestral continuum analogous to our family structure', while English speakers conceptualise Heaven as having the 'connotations of transcendence and spirituality' (Hall and Ames (1995) p.xvi). Based on these concepts, philosophers develop beliefs, knowledge, arguments, etc., which they hope to be persuasive in their respective tradition.

But the stock of concepts of each tradition seems to be the product of a specific historical and cultural circumstance of the tradition. As Rosemont (1988) argues:

our basis cognitive framework - which ranges from our unreflective conception of what it is to be a human being to our assumptions, beliefs, and presuppositions about the general features of the physical universe - is overwhelmingly determined for us by a set of highly specific environmental circumstances ranging from social relations accompanying stages of history and of culture, to the syntactical particularities of our native tongue. To be is to be the value of a pronoun form - and an indexical at that. (p. 37)

If a tradition is indeed based on historical and cultural circumstances, then, being situated in a particular historical and cultural context, we seem to have a difficulty in accessing concepts foreign to our tradition. At best, we can translate and understand the traditions other than our own only my super-imposing our concepts onto others. Rosemont (1988) continues:

If, however, the producers of those texts came from cultures very different from the contemporary West - and it is obvious that they did - and if the languages in which they wrote have phonetic, syntactic, and semantic properties very different from, say, contemporary English - and it is obvious that they do - then what reasons can be given for believing that we might ascertain, even in principle, what those texts said to the people who could read them at the time of compositions? Can we really translate and interpret Sanskrit, classical Chinese, or other nonwestern texts without imposing our own linguistic, cultural, historical, ontological, and other 
categories thereon? Must these texts not ultimately be seen as a series of sophisticated Rorschach blots? (p. 38)

If the concepts used in a philosophical discourse are specific to the historical and cultural circumstance of a particular tradition, we may ask how comparisons between traditions can be entertained?

\subsection{Davidson on Conceptual Scheme}

The difficulty enunciated above seems to play the central role in Davidson's (1984) discussion of conceptual relativism. Davidson argues that the notion of conceptual relativism is incoherent. The notion that he rejects is based on what he calls conceptual schemes:

Conceptual schemes, we are told, are ways of organising experience; they are systems of categories that give form to the data of sensation; they are points of view from which individuals, cultures, or periods survey the passing scene. (p. 183)

Conceptual relativism is then the doctrine that what is real is relative to a conceptual scheme:

Reality itself is relative to a scheme: what counts as real in one system may not be in another. (p. 183)

An example of this claim is Whorf who famously argued that the Hopi conceptualise reality differently from Westerners due mainly to a different conception of time.

In arguing for conceptual relativism, Whorf claims that:

language produces an organisation of experience. We are inclined to think of language simply as a technique of expression, and not to realise that language first of all is a classification and arrangement of the stream of sensory experience which results in a certain word-order. (Quoted in Davidson (1984) p. 190)

By following Whorf, Davidson associates a conceptual scheme with a language.

We may accept the doctrine that associates having a language with having a conceptual scheme. The relation may be supposed to be this: where conceptual schemes differ, so do languages.

This does not mean, however, that a speaker of one language necessarily organises their experience differently from a speaker of another language. For a language may be translated into another by invoking only once conceptual scheme. For example, 'blanc' is a French word for 'white'. One need not think that 'blanc' and 'white' give rise to two 
different concepts; rather, they both express one concept, i.e., white or whiteness. As Davidson writes, 'Studying the criteria of translation is therefore a way of focusing on criteria of identity for conceptual schemes' (p. 184).

Conceptual relativism thus means the failure of the 'intertranslatability' of languages. Showing the existence of languages which are not translatable is tantamount to making a case for conceptual relativism. We may then ask the question of whether there are any languages which are untranslatable?

In addressing this question, Davidson considers two kinds of failures of translatability: complete and partial. A case of complete failure is when a language cannot be interpreted as a language. For instance, if an English speaker were to meet an alien, it is more likely that the two would be unable to communicate. This would not necessarily be because the English speaker had not developed an alien dictionary but because the language would not be recognised as such other than being a mere sequence of noise. The alien's language would not be identified as a language which failed to be intertranslated as, in this case, the alien's language would not be identified as a language at all. Thus, an alien cannot establish the case for conceptual relativism.

As mentioned above, Davidson also considers cases of partial failure in the intertranslatability of languages. The case of partial failure assumes that one language shares a common 'part' with other languages. The suggestion is that the failure of intertranslatability can be understood by referring to the common part which acts as a neutral ground from which the failure of intertranslatability can be identified. The common part, however, cannot be part of the languages, since what is to be forged is the intertranslatability of these languages themselves. Nor can they be beliefs and other mental attitudes, as it is not clear how we can understand a person's beliefs without understanding their language. Furthermore, we can not understand a person's language if we do not know their beliefs and attitudes which serve as the neutral ground. Thus, it is not clear how we are to understand the failure of the person's language to be intertranslated.

We may respond by arguing that two people can come to have a general agreement on beliefs. They can simply stipulate what is to be believed for the sake of communication. However, this agreement could only be reached in the same language. Hence such a situation does not invoke a language which is untranslatable. Moreover, even if they arrived at a general agreement on beliefs, in coming to identify an untranslatable language, 'contrasts can be explained and described using the equipment of a single language' (p. 184). If the differences can be explained and described, that is because of the common language that they use to do so. Again, then, an untranslatable language makes no appearance.

Therefore

we could not be in a position to judge that others had concepts or beliefs radically different from our own. (. 197)

Thus, conceptual relativism cannot be shown to be true. ${ }^{\text {ii }}$ 


\section{2 ... and Comparative Philosophy}

The crux of Davidson's argument against conceptual relativism is that a person is unable to step outside of their own conceptual scheme. All our effort to understand another's conceptual scheme requires a translation into our own conceptual scheme. Otherwise, we would be unable to understand how others organise their experiences. However, since we cannot step outside of our own conceptual scheme, we cannot even refer to another's conceptual scheme as such, let alone put ourselves into another's shoes. Hence, conceptual relativism cannot be established. For there is only one conceptual scheme involved in our investigation.

Is a comparison of the concepts which seem to undergrid comparative philosophy then impossible? If Davidson is right, we cannot have insight into how and why concepts differ in different traditions. In such case, we cannot make sense of the idea that philosophical traditions differ conceptually and hence we would be unable to even conceive of the existence of these different traditions. For example, give 'our [western] unreflective conception of what it is to be a human being' (Rosemont (1988) p.37, as quoted above), Western philosophers would be unable to understand the Chinese unreflective conception of what it is to be a human being. Thus, how can the activities of comparative philosophy possible be carried out?

\subsection{The Possibility of Comparative Philosophy}

By referring to Alasdair MacIntyre who 'bring[s] out the differences between Aristotle's virtue-based theory and contemporary rights-based theories' (Rosemont (1988) footnote 37, p.63), Rosemont (1988) argues against Davidson by contending that his use of 'our' is ambiguous

If it simply refers to mature English (and related modern western language) speakers, it is unexceptional. But if "our" refers to contemporary western moral philosophers [or contemporary western philosophers], his claim is suspect; and it is only the latter, and not the former, that MacIntyre (and comparative philosophers) challenge, so the seeming paradox is resolved. (footnote $37, \mathrm{p} .63$ )

Consider, for example, the early Confucians who built a concept cluster of 'ethics' that does not involve 'the "rights-based" concept cluster of morals developed in modern western culture' (Rosemont (1988) p.63). However, this does not mean that ethical concepts do not exist in the discourses of early Confucians. Rather, it is that they cannot be found merely on the assumption that ethics is a matter of rights-based morals understood according to the contemporary Western philosophers.

Yet, how can early Confucian ethics be explained without relying on the rightsbased concept cluster of morals used by Western philosophers? By extension, how can Chinese concepts be given comparative light while Western concepts may not be likewise analysed? In coming to answer this question, Rosemont argues 
My earlier arguments against conceptual relativism were obviously grounded in the belief that whatever can be said in any one natural human language can be said in any other if the full richness, variation, and capacity for change in human languages be exploited; and it is to nonwestern texts that I think we should now turn for much of the enrichment and change. (p.69)

However, Rosemont (1988) does not seem to explain how 'the full richness, variation, and capacity for change in human languages be exploited'. In order to explain why Davidson's claim is suspect and thus demonstrate the possibility of comparative philosophy, we must provide an explanation for how that can be done. Only then would we be in a position to show how comparing Chinese and Western traditions of philosophy can be a meaningful activity.

\subsection{Presuppositions}

An approach towards the issue at hand can be found in the works of David Hall and Roger Ames. Hall and Ames (1995), while primarily focusing on comparative philosophy rather than Chinese philosophy per se, analyse 'Chinese concepts' by illuminating the presuppositions that underlie Chinese philosophy in contrast to those which underlie Western philosophy. They provide presuppositions, what they call first and second problematics, that have historically shaped the fabrics of Chinese and Western traditions of philosophy. Presuppositions are 'usually unannounced premises held by the members of an intellectual culture or tradition that make communication possible by constituting a ground from which philosophic discourse proceeds' (Hall and Ames (1987) p.11).

In order to enforce the idea of presuppositions, consider one of the gestalt pictures, such as the duck-rabbit picture. When the picture is presented for the first time, it appears to some as a picture of a duck and others as a picture of a rabbit, despite the fact that they are all sighting the same thing. Depending on the visual orientation a person as at the time, the picture may appear and be 'seen' differently. Only with the same, or at least similar, visual orientation, is the picture 'seen' as the same thing. To be able to explain what a person 'sees', then, we need to forge an elucidation of the person's orientation that others can adopt so that they can come to an understanding of what the other experiences.

Hall and Ames (1995) approach Chinese and Western presuppositions with an attention to the historical development of the conceptual system of each tradition. They provide a historical study describing how the first problematic, or analogical/correlative, thinking came to dominate Chinese philosophising and how the second problematic, or causal, thinking came to dominate Western philosophising. Though they do not explicate their enterprise in this way, Hall and Ames' elaboration can be understood as laying out the 'map[s] of the metaphors discernible in the commonly used expressions in our language communit[ies]' (Potter (1988) p.31). Thus, English speakers associate the expression 'Heaven' with the spiritually transcending realm, which is then associated with God who is responsible for the causal order of the universe. The Chinese speakers, 
on the other hand, associate tian with the ancestral structure, which then analogically adumbrates our family structure.

Comparing presuppositions is then a way of drawing 'graphic explication[s] of the conceptual system or systems shared by members of the communit[ies] of speakers of [English, Chinese and so on]' (Potter (1988) p.31). They do so by providing association networks of concepts. In this way, the historical development of the conceptual system of each tradition can be explicated. This results in a conceptual map or a set of conceptual clusters picturing the way the concepts depend on and relate to each other.

A focal point of this elaboration of Hall and Ames' approach is that the Chinese map does not invoke concepts which are totally foreign to Western philosophers. Even though Westerners do not associate a family structure with the word and the concept 'Heaven', the concept of family structure is present in the Western conceptual system. It is just that the concept entails a different set of associations or metaphors for Westerners than Chinese. In comparatively philosophising, therefore, the objects of comparisons are the ways that concepts are linked rather than concepts themselves. It is the ways in which concepts form equilibrium that are compared and contrasted in a comparative philosophical way.

\subsection{Davidson Revisited}

As we have seen, the possibility of comparing Chinese and Western traditions of philosophy does not necessarily imply the transcendence of our concepts. The backbone of Davidson's thesis against conceptual relativism is therefore not rejected. What is rejected is the claim that 'ways of organizing experience', 'systems of categories that give form to the data of sensation' and 'points of view from which individuals, cultures, or periods survey the passing scene' (p.183) cannot be shown as relative.

Let us consider again the duck-rabbit gestalt picture. Depending on a person's visual orientation, they organise the experience of 'seeing' the picture, evoke a system of categories either as a duck or a rabbit, and therefore view the picture in a certain way. We can compare different ways of doing these activities based on our visual orientations. By analogy, traditions of philosophy can be given comparative light by examining the networks of concepts that are manifested in the expressions of the members of each tradition. Thus, for instance, depending on the conceptual association, a person may experience something as a family structure such as tian for the Chinese, or as the spiritually transcendent realm of the Western Heaven.

What a person experiences is therefore relative to their conceptual scheme. Where conceptual association differs, experience differs. In this way, a comparative philosopher can reject the application of Davidson's thesis to comparative philosophy and thus demonstrates the possibility of comparative philosophy. 


\section{Comparative Philosophy vs. Western Philosophy}

Having shown how comparative philosophy is possible, our analysis now turns its head and demands an analysis of its own. Despite our agreement with Davidson on the impossibility of transcending our concepts, we provided a meta-view from which to survey the activities of comparative philosophers. However, we may ask how this metaview can be explained in our frame of thought?

An answer to this question is, perhaps, dependent on the tradition of philosophy that has cultivated our philosophising. Indeed, philosophising is a culturally oriented activity. 'It necessarily draws on a cultural legacy for its terminology, conceptualisation of problems, and even relevance. Philosophy develops not in total isolation but within a community of discourse' (Kasulis (2002) p.14). Even a comparative philosopher cannot escape this situation. As Rosemont (1988) argues

no comparative scholar can come to another culture as a tabula rasa. One need not be a committed relativist to admit that pure (culture-free) intellectual endeavour is a myth: physicians, scholars and scolds, plain men and philosopher queens are one and all ineradicably influenced by their cultural and historical circumstances. (pp. 65-6)

The dominant understanding of philosophising in the West is possibly that it is 'a means of bridging contexts, cultures, time, and place' (Kasulis (2002) p.15). However, this claim can only be made due to the cultural and historical background from which Western philosophy grew, i.e., the ideas of the Greeks together with the influence of Christianity.

So '[w]e do not argue philosophy; we argue in or through philosophy (Kasulis (2002) p.157 emphasis original). Likewise, as comparative philosophers communicating to English-speaking philosophers, we also argue in and through the conceptual association that is shared by Western philosophers. That is why Whorf, for instance, advanced Hopi metaphysics as incommensurable to Western metaphysics to us in clear English. ${ }^{\text {iii }}$

This way of analysing comparative philosophy may be seen as 'favor[ing] philosophical boundaries of European thought since Descartes for identifying conceptual problems in general' (Larson (1988) p.11). By admitting that our comparative philosophy is framed in terms of our philosophical enterprise, we may be accused that '[a]genda items for comparative philosophizing have been selected from ethics, epistemology, philosophy of language, and so forth...' (Larson (1988) pp.11-12).

Even the demarcation of what counts as philosophy itself may be thought of as a Western invention. In a comparative study, we look for something in another culture which resembles philosophy to us, i.e., Western philosophers. Consider a wooden statue created as a 'sacred' monument, to which people make offerings and pray for a successful harvest, a successful battle and so on. However, as Blocker and Starling (2001) point out, it is not clear 'which part of this complex is their "art", which part is "religion", which part is "agriculture", and so on' (p.16) even though we, as Western philosophers, can separate them and be interested in their "art", their "religion" or their "agriculture" separately. 
Even if Western philosophers appeal to the categories of conceptual clusters that are specific to their philosophical tradition, it does not follow that the Chinese map that is made available to them misses the mark entirely. In the same way that a concept may have tradition-specific associated concepts, the concept clusters that each category gives rise to may not be absolute. For instance, the early Confucian ethics is associated with concepts other than the rights-based concept cluster of morals of the contemporary Western philosophers. If we consider different conceptual clusters, Western philosophers can make sense of early Confucian ethics, particularly in comparison with contemporary Western ethics.

\section{Boundaries of Comparisons}

By self-reflection on our analysis of comparative philosophy, we seem to be able to show that the demarcation between traditions is based on the conceptual clusters of the comparative philosopher. As Potter (1988) argues:

difference in conceptual system is assumed by the investigator, and differences between persons, cultures, or philosophers is thus made to fit differences in meanings of segments, pieces of behaviour, and specific categories. In truth, the choice of boundaries across which to compare is the same choice as that among categories of investigation; as we saw, it is the practical concerns of the investigator which ultimately dictate these boundaries, they are not absolutely there to be discovered in the material investigated. (p.24)

As we discussed above, the activities surrounding a wooden statue cannot be demarcated into art, religion, agriculture and so on in an absolute sense. The demarcation can be made only in virtue of the categorisation performed via a tradition of thought in which the philosophical thought has been cultivated.

This seems to suggest that Western philosophers can come to understand Chinese art, Chinese religion, Chinese agriculture and so on, from the basis of their Western philosophical categories. This does not imply, however, that a translation and an understanding of the Chinese tradition by Westerners can be obtained only by superimposing their concepts onto those of the Chinese. Rather, despite the fact that Western philosophers are accustomed to associate each category with particular concept clusters, it is only from this basis that they can learn other associations. For example, they can learn to associate a family structure with the expression tian, from qualifications made to the translated term 'Heaven'. Though the choice of the boundaries of comparisons may be thought to suggest that a different tradition of philosophy is to be understood in an investigator's individual way, it is the flexibility of the boundaries that gives rise to the possibility of understanding other traditions and thus that of comparative philosophy.

As discussed in relation to Davidson's thesis against conceptual relativism, Westerners may associate words and the concepts differently from the Chinese. It is only that Westerners carve up their activities differently from the Chinese rather than that the 
two have incommensurably different concepts. It is from the basis of the boundaries set by the comparative philosopher that comparative philosophical studies proceed.

\section{References}

1. Blocker H. Gene and Christopher I. Starling (2001) Japanese Philosophy, State University of New York Press, Albany

2. Davidson, Donald (1984) 'On the Very Idea of a Conceptual Scheme', Inquiries into Truth \& Interpretation, Clarendon Press, Oxford, pp. 183-98

3. Hall, David L. and Roger T. Ames (1987) Thinking Through Confucius, State University of New York Press, Albany

4. Hall, David L. and Roger T. Ames (1995) Anticipating China, State University of New York Press, Albany

5. Hansen, Chad (1992) Language and Logic in Ancient China, University of Michigan Press, Ann Arbor

6. Hansen, Chad (1992) A Daoist Theory of Chinese Thought, Oxford University Press, Oxford

7. Kasulis, Thomas P. (2002) Intimacy or Integrity, University of Hawaii Press, Honolulu

8. Larson, Gerald James (1988) 'Introduction: The "Age-Old Distinction Between the Same and the Other", Interpreting Across Boundaries, G.J. Larson and E. Deutsch (eds.), Princeton University Press, Princeton

9. Parkes, Graham (1987) 'Introduction', Heidegger and Asian Thought, Graham Parkes (ed.), University of Hawaii Press, Honolulu

10. Potter, Karl H. (1988) 'Metaphor as Key to Understanding the Thought of Other Speech Communities', Interpreting Across Boundaries, G.J. Larson and E. Deutsch (eds.), Princeton University Press, Princeton

11. Rosemont, Henry Jr. (1988) 'Against Relativism', Interpreting Across Boundaries, G.J. Larson and E. Deutsch (eds.), Princeton University Press, Princeton. 
${ }^{\mathrm{i}}$ There has been a vast amount of literature presenting non-Western philosophies in this way, for example D.T.Suzuki in his presentations of Zen Buddhism. See also Hansen (1983) ch.1 in the context of Chinese philosophy. One thing which is never clear in such literature is their use of 'logic'. Logic, for a

contemporary Western logician, is about validity of arguments. It is about what proposition or sentence, i.e., conclusion, follows from what propositions or sentences, i.e., premises; it is not about what propositions or sentences make sense. The special logic resort does not seem to conform to this standard account of 'logic'.

${ }^{\text {ii }}$ We can frame the problem that Davidson points out in terms of Zhuangzi, at least Zhuangzi according to Hansen (1992). If Hansen is correct in his interpretation, Zhuangzi was concerned with the basis for our discriminations giving rise to our acceptance and rejection of our social 'conventions'. Zhuangzi argues that there is no perspective which we can accept to settle the issue of which convention to accept and which to reject. For the basis of the acceptance and the rejection of that perspective must also be in question. All we can do is accept of reject a discrimination pattern based on a certain perspective, the perspective that we happen to have accepted for whatever the reason. There is no way to get to the common basis from which we can settle the issue. However, to present Zhaungzi's perspective is an issue that concerns the study of this paper. Given that the paper is written in English, addressing issues to English-speaking philosophers, framing the problem of comparative philosophy in terms of Davidson seems to avoid begging the question. iii Cf. Rosemont (1988) pp.49-50 